\title{
Reconstruction of F2 layer peak electron density based on operational vertical total electron content maps
}

\author{
T. Gerzen, N. Jakowski, V. Wilken, and M. M. Hoque \\ German Aerospace Center (DLR), Institute of Communications and Navigation, Kalkhorstweg 53, 17235 Neustrelitz, \\ Germany
}

Correspondence to: T. Gerzen (tatjana.gerzen@dlr.de)

Received: 22 August 2012 - Revised: 7 June 2013 - Accepted: 18 June 2013 - Published: 23 July 2013

\begin{abstract}
Electron density is the major determining parameter of the ionosphere. Especially the maximum electron density of the F2 layer in the ionosphere, $N m \mathrm{~F} 2$, is of particular interest with regard to the HF radio communication applications as well as for characterizing the ionosphere. In this paper we present a new method to generate global maps of $N m \mathrm{~F} 2$. The main principle behind this approach is to use the information about the current state of the ionosphere included in global total electron content (TEC) maps as well as the relationship between total electron content, equivalent slab thickness and F2 layer peak density. Modeling of slab thickness is an interim step in our reconstruction approach. Thus, results showing the diurnal and seasonal variations and effects of solar activity on the modeled slab thickness values are given.

In addition a comparison of the reconstructed $N m \mathrm{~F} 2$ maps with measurements from several ionosonde stations as well as with the global $N m \mathrm{~F} 2$ model NPDM is presented.

Since 2011 the described method has been used at DLR Neustrelitz to generate $N m \mathrm{~F} 2$ maps as operational service. These maps are freely available via the Space Weather Application Center Ionosphere SWACI (http://swaciweb.dlr.de).
\end{abstract}

Keywords. Ionosphere (Plasma temperature and density)

\section{Introduction}

The ionosphere is the ionized part of the Earth's upper atmosphere between about 50 and $1000 \mathrm{~km}$ above the Earth's surface. The solar radiation and particle precipitation control the temporal and spatial variation of the ionization level in this near-Earth space strongly depending on day of year (doy), time of day and geographic location. At all latitudes the ionosphere is commonly supposed to separate into layers (D, E, F1 and F2). Typically the E and F layers are described by critical frequencies $f_{o \mathrm{E}}, f_{o} \mathrm{~F} 1$ and $f o \mathrm{~F} 2$ and peak heights $h m \mathrm{E}, h m \mathrm{~F} 1$ and $h m \mathrm{~F} 2$. The critical frequency is the limiting frequency at or below which a radio wave is reflected by an ionospheric layer at vertical incidence. Associated with each critical frequency is a peak electron density $N m \mathrm{E}, N m \mathrm{~F} 1$ and $N m \mathrm{~F} 2$.

The most ionized and most variable region of the ionospheric layers is the F2 region. This region extends from about $200 \mathrm{~km}$ above the Earth's surface to $500 \mathrm{~km}$ depending on the season, time of day, geographical location and level of solar activity. The peak daytime electron density in the F2 region for mid-latitude locations is usually reached one hour after midday around $300 \mathrm{~km}$ and typically decreases after sunset. The maximum electron density, $N m \mathrm{~F} 2$, of the F2 layer may reach up to $10^{13} \mathrm{elm}^{-3}$. For more details we refer to Davies (1990).

From the application perspective especially with regard to the high-frequency (HF) radio communication applications, the F2 layer peak density or the critical frequency $f o \mathrm{~F} 2$ is of particular interest. $f o \mathrm{~F} 2$ in $\mathrm{MHz}$ is related to $N m \mathrm{~F} 2$ in electrons per cubic meter according to

$$
N m \mathrm{~F} 2=1.24 \times 10^{10}(f o \mathrm{~F} 2)^{2} .
$$

The critical frequency builds the lower limit for the maximum usable frequency, MUF. MUF is the upper frequency that can be used for terrestrial transmission independent of transmitter power. A HF signal transmission can be interrupted or even lost due to regular and irregular variations of the bottom side plasma density including the $N m \mathrm{~F} 2$. Moreover, the knowledge of $N m \mathrm{~F} 2$ is required to mitigate 
higher-order ionospheric propagation effects such as ray path bending errors in precise positioning (Hoque and Jakowski, 2008) using Global Navigation Satellite Systems (GNSS). Therefore, the availability of $N m \mathrm{~F} 2$ maps containing the information about the current values of the peak electron density is of great use for both ionospheric research and GNSS applications.

Due to the fact that direct measurements of the electron density are hardly possible and very costly, GNSS has become the premier tool for measuring, monitoring and reconstructing the ionosphere. The information about total electron content, TEC, along the receiver-to-satellite ray path $s$ can be obtained from the dual-frequency measurements permanently transmitted by GNSS satellites. This measured slant $\mathrm{TEC}_{s}$ in TECU (TECU $=10^{16} \mathrm{~m}^{-2}$ ) is related to the electron density $N_{\mathrm{e}}$ by

$\mathrm{TEC}_{s}=\int_{s} N_{\mathrm{e}}(h, \varphi, \lambda) d s$,

where $N_{\mathrm{e}}$ depends on the altitude $h$, geographical latitude $\varphi$ and longitude $\lambda$. To make the geometry-dependent measured $\mathrm{TEC}_{s}$ data usable for any GNSS user, slant TEC is often transformed to vertical TEC, vTEC. Vertical TEC at the geographical location $\left(\varphi_{0}, \lambda_{0}\right)$ is the integral of the electron density profile

$\operatorname{vTEC}\left(\varphi_{0}, \lambda_{0}\right)=\int_{h} N_{\mathrm{e}}\left(h, \varphi_{0}, \lambda_{0}\right) d \boldsymbol{h}$,

where $\boldsymbol{h}$ is the vertical straight line from satellite altitude to the ground station altitude through $\left(\varphi_{0}, \lambda_{0}\right)$. We can gain an approximation to vTEC by means of a projection from measured slant $\mathrm{TEC}_{s}$ to vertical at a piercing point $\left(\varphi_{\mathrm{p}}, \lambda_{\mathrm{p}}\right)$ on the ray path $s$ in a suitably chosen single-layer-ionosphere height $h_{\text {sp. }}$. Therefore usually a common single-layer mapping function depending on the elevation angle $\epsilon$ of $s$ and Earth radius $R$ according to

$$
\begin{aligned}
\operatorname{vTEC}\left(\varphi_{\mathrm{p}}, \lambda_{\mathrm{p}}\right) & =\frac{\mathrm{TEC}_{s}}{M(\epsilon)} \text { with } \\
M(\epsilon) & =\left(1-\left(\frac{R \cos (\epsilon)}{R+h_{\mathrm{sp}}}\right)^{2}\right)^{-1 / 2}
\end{aligned}
$$

is used.

Our reconstruction of the peak electron density of the F2 layer will benefit from using another key parameter of the ionosphere - the equivalent slab thickness $\tau$. By means of $\tau$ the variability of vTEC can be transferred into the variability of F2 layer peak electron density. The equivalent slab thickness provides a good estimation of the width of the vertical electron density profile. It is defined by the ratio of vertical TEC and the F2 layer peak density $N m \mathrm{~F} 2$ according to

$\tau=\frac{\mathrm{TEC}}{N m \mathrm{~F} 2}$ all in SI units.

In the present paper we present a new method of reconstructing global maps of $N m \mathrm{~F} 2$ using TEC maps. Employing the ionospheric measurements in order to improve the performance of the ionospheric models, especially for ionospheric conditions far from average undisturbed period behavior, is a forefront topic of the ionospheric research. The last 20 years have seen a rapid growth in the development and use of ionospheric reconstruction techniques. As mentioned above, TEC is the most available and thus a very important source of information about the ionosphere. The groundbased TEC measurements can be used directly to produce two-dimensional maps of the ionosphere. There are several 2-D approaches to reconstruct vTEC (cf., e.g., Jakowski et al., 2011b; Hernández-Pajares et al., 2002).

However, the information on the vertical distribution of the electron density is mostly lost with these 2-D mapping algorithms. Within the last 10 years the investigation on the ionospheric 3-D electron density reconstruction tended to focus above all on the data assimilation techniques. The Electron Density Assimilative Model (EDAM) was developed at QinetiQ to assimilate measurements into a background ionospheric model (Angling and Khattatov, 2006; Angling and Cannon, 2004). The Ionospheric Data Assimilation ThreeDimensional (IDA3D), an ionospheric objective analysis algorithm, was developed by Bust and Mitchell (2004). IDA3D uses a three-dimensional variational data assimilation technique (3DVAR) to incorporate available data into a background specification on a global grid. The Global Assimilation of Ionospheric Measurements (GAIM) model was developed by Utah State University as a Kalman filter assimilation algorithm (Scherliess et al., 2004). An overview of several ionospheric reconstruction methods can be found also in Bust and Mitchell (2008).

The main purpose of the current paper is to present our new method of generating $N m \mathrm{~F} 2$ maps and to give a first impression on the quality of this method. The paper is organized as follows: in Sect. 2 the database used for the reconstruction is described. In Sect. 3 we elaborate the reconstruction approach for F2 layer peak electron density in detail, also showing a reconstructed $N m \mathrm{~F} 2$ map. Modeling of the slab thickness is an interim step in our reconstruction approach. Thus, results showing the variations and effects of seasons and solar activity on the modeled slab thickness values will be presented in Sect. 4. Afterwards in Sect. 5 first validation results of the reconstructed $N m \mathrm{~F} 2$ maps are presented. And finally, in the last section conclusions are given.

\section{Database}

The main inputs for our reconstruction are the actual TEC maps, time and location specifications and solar radio flux index F10.7 as a measure for the solar activity. Furthermore, the deployment of TEC and $N m \mathrm{~F} 2$ models plays an important 
role. We use the Neustrelitz global TEC model (NTCM-GL) (Jakowski et al., 2011a) to model TEC and the Neustrelitz Peak Density Model (NPDM) (Hoque and Jakowski, 2011) to model $N m$ F2. It should be mentioned that for modeling of this ionospheric parameters any other models can be used within the reconstruction.

GPS measurements of more than 100 ground-based stations provided by the global international GNSS service (IGS) network are currently used at DLR Neustrelitz to generate TEC maps. To calculate a TEC map, the measured slant TEC is converted to vertical TEC using the single-layer mapping function (cf. Eq. 4). Afterwards these vTEC values are assimilated into the operational version of the Neustrelitz global TEC model NTCM-GL by means of a combination of a least squares method and an empirical assimilation approach (Jakowski et al., 2011b). The global TEC maps are routinely generated with updates every $5 \mathrm{~min}$ and are freely available via SWACI (http://swaciweb.dlr.de). These TEC maps build the database for our reconstruction.

\section{Reconstruction approach for F2 layer peak electron density maps}

As former studies have shown (cf. Jakowski et al., 1990; Davies and Liu, 1991), the equivalent slab thickness is very helpful in studying dynamic processes in particular during ionospheric storms. Under unperturbed conditions the equivalent slab thickness behaves much smoother than TEC and $N m \mathrm{~F} 2$, which are highly correlated with the ionizing EUV radiation approximated, e.g., by the solar radio flux index F10.7 (cf. Unglaub et al., 2011). Under equilibrium conditions between ionization and recombination the slab thickness is proportional to the scale height of the thermosphere according to the Chapman theory (Davies, 1990). Assuming a thermospheric scale height on the order of $50-80 \mathrm{~km}$ (cf. Stankov and Jakowski, 2006) the equivalent slab thickness typically ranges during daytime between about 200 and $400 \mathrm{~km}$ height. Following the temperature profile in the thermosphere during daytime, scale height and equivalent slab thickness peak $1-2 \mathrm{~h}$ after local midday. During nighttime, when plasma loss is dominating, plasma redistribution and plasma transport often increase the equivalent slab thickness. Thus, equivalent slab thickness may reach $600 \mathrm{~km}$ and even more when plasma transport from the plasmasphere seriously affects the ionosphere, thus causing so-called nighttime enhancements. Under perturbed conditions the equivalent slab thickness may deviate from mean behavior by more than $20 \%$ as shown by Jakowski et al. (1990).

Besides the diurnal variation with additional peaks in the morning and evening hours the equivalent slab thickness shows also dependencies from season, geographic and geomagnetic location and solar activity, the latter to a much lesser extent than the composing quantities TEC and $N m \mathrm{~F} 2$ (cf. Jakowski et al., 1981; Miro et al., 1999; Jayachandran et al., 2004; Chuo, 2007). For mid-latitudes numerous slab thickness models have been published during the years (cf. Kersley and Hajeb-Hosseinieh, 1976; Davies and Liu, 1991; Huang, 1983), showing the importance of this parameter for describing the ionosphere.

Neglecting in a first approach severe perturbations and vertical plasma transport processes, it can be stated that the slab thickness is rather stable on average due to the close relationship to the thermosphere and therefore suited to transform variations of TEC into $N m \mathrm{~F} 2$ and vice versa. Principally, this transformation will work during daytime better than at nighttime and under unperturbed conditions better than during ionospheric storms. Considering the relationship between TEC and $N m F 2$ we assume that small changes in TEC values lead first of all to the corresponding changes of $N m \mathrm{~F} 2$ values, whereas $\tau$ values remain almost unaffected (cf. Jakowski et al., 2010; Leitinger et al., 2004). Within the reconstruction procedure we use this dependency to reconstruct the values of $N m \mathrm{~F} 2$, applying modeled slab thickness values together with actual vTEC values.

In the first step of the F2 layer peak electron density reconstruction algorithm we model the values of TEC and $N m \mathrm{~F} 2$ by means of the models NTCM-GL and NPDM, respectively. The model values are calculated for a latitude/longitude grid based on the input parameters doy, time of day and F10.7. The F10.7 index is used as a proxy of the solar activity. Both models need only few coefficients as well as empirically fixed parameters and provide results comparable with the NeQuick Model (cf. Nava et al., 2008) and have at the same time the advantage of being very fast (cf. Jakowski et al., 2011a; Hoque and Jakowski, 2011).

In the next step we employ the modeled $\mathrm{TEC}_{\text {mod }}$ and $N m \mathrm{~F} 2_{\text {mod }}$ to calculate slab thickness according to the relation given by Eq. (5). Now regarding the comparison results between the measured TEC and NTCM-GL-modeled TEC given in Jakowski et al. (2011a) we can assume, on average, relatively small residuals between the modeled TEC values and the TEC map values. Under these conditions we can expect the slab thickness computed for the model TEC values to stay almost unchanged and to be "valid" for the TEC map values. Thus, in the last reconstruction step we combine this modeled slab thickness data and the current TEC map to determine the $N m \mathrm{~F} 2$ map according to

$N m \mathrm{~F} 2_{\text {rec }}=\frac{\mathrm{TEC}_{\text {map }}}{\tau}$.

Figure 1 illustrates the basic concept of $\mathrm{NmF} 2$ reconstruction. Figure 2 shows the NPDM model values of $N m \mathrm{~F} 2$ in comparison with the corresponding $N m \mathrm{~F} 2$ reconstruction for 23 July 2011, 03:00 UT. The right picture presents the model values, the left one the reconstructed $N m \mathrm{~F} 2$ map. Both pictures present the electron density values color coded and also the counter lines. As expected, the general ionospheric conditions are comparable in both pictures. We observe that both model and reconstruction calculate electron density values 


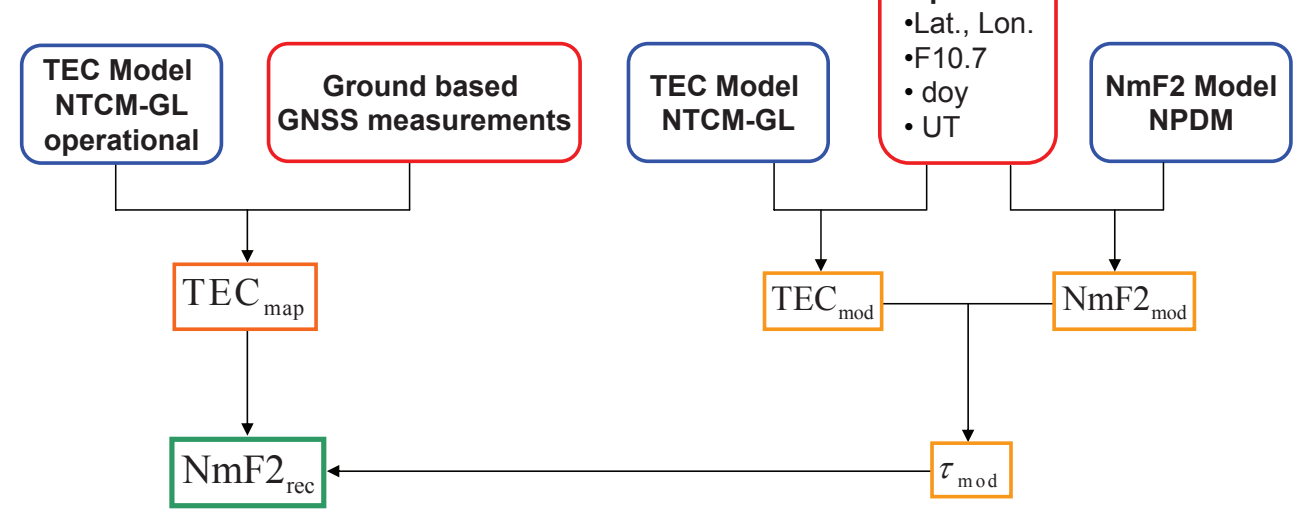

Fig. 1. Diagram of $N m \mathrm{~F} 2$ reconstruction approach.

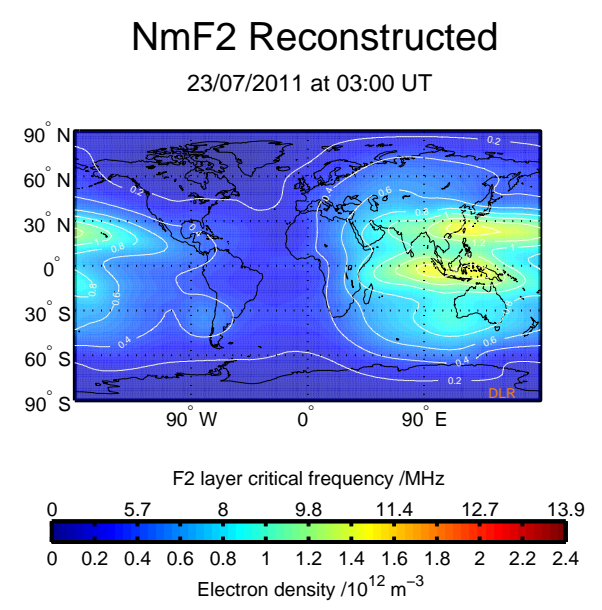

(a) Reconstructed $N m F 2$ map

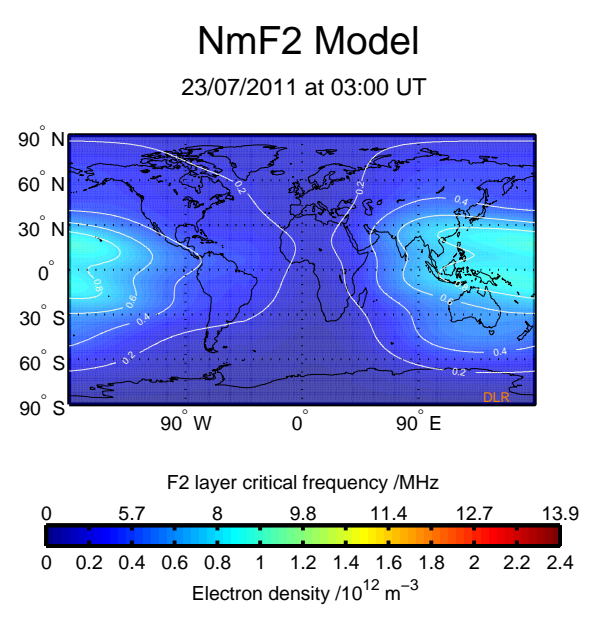

(b) Model $N m F 2$

Fig. 2. Reconstructed $N m \mathrm{~F} 2_{\text {rec }}$ and modeled $N m F 2_{\text {mod }}$ for 23 July 2011, 03:00 UT.

under $0.2 \times 10^{12} \mathrm{~m}^{-3}$ in the polar regions and locate the peaks of the ionospheric crest region around the same local time. In total the reconstruction calculates higher values than the model. This is particularly noticeable for the ionospheric crest region. A detailed comparison of the reconstructed and modeled $N m \mathrm{~F} 2$ values with measurements from several ionosonde stations is presented in Sect. 5.

The described algorithm can be run on a global or a local grid. Currently it routinely generates global $N m \mathrm{~F} 2$ maps with spatial resolution of $2.5^{\circ}$ latitude, $5^{\circ}$ longitude and time resolution of $5 \mathrm{~min}$, similar to the TEC maps. However, the algorithm can be easily modified to a higher-resolution grid. The F2 layer peak electron density maps are offered to users via the operational data service SWACI (http://swaciweb.dlr.de) at DLR Neustrelitz.

It should be mentioned that our reconstruction approach is not an assimilation of measurements into the model. The used $N m \mathrm{~F} 2$ model is applied just for calculation of the model slab thickness values. As already stated above, currently the models NTCM-GL and NPDM are deployed within the reconstruction, but also any other TEC and $N m \mathrm{~F} 2$ models can be applied to use the algorithm.

Although the approach considers only TEC measurements and no direct $N m \mathrm{~F} 2$ measurements, it has the great advantage of providing users reasonable results at each point over the globe with a $5 \mathrm{~min}$ time resolution because of the availability of a comparatively huge amount of real-time TEC measurements. It is very fast and can be easily modified to run regionally with an arbitrary resolution.

\section{Results on the modeled slab thickness}

Modeling the slab thickness is not a primary aim of this work, but an interim result during the reconstruction of the F2 layer peak electron density. Nevertheless, representative results on the modeled slab thickness are presented in this section to 


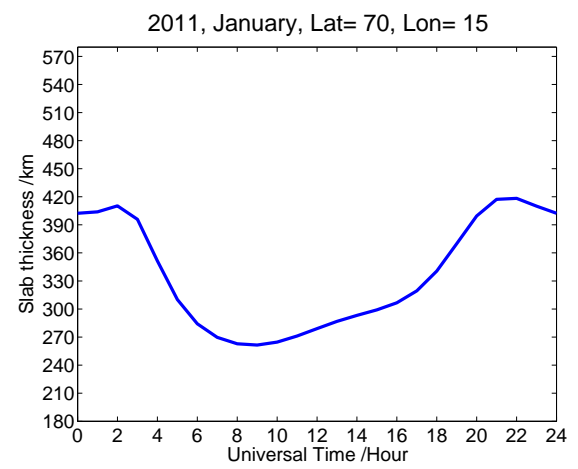

(a) January, Lat $=70 \mathrm{~N}$

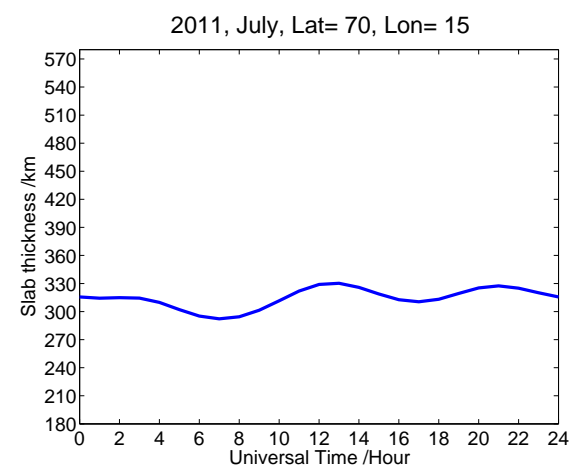

(d) July, Lat $=70 \mathrm{~N}$

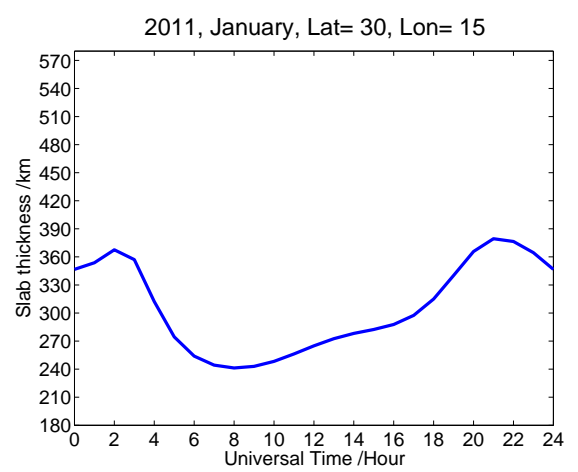

(b) January, Lat $=30 \mathrm{~N}$

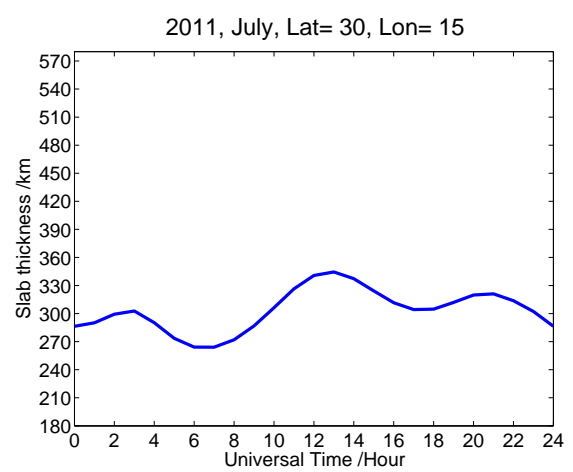

(e) July, Lat $=30 \mathrm{~N}$

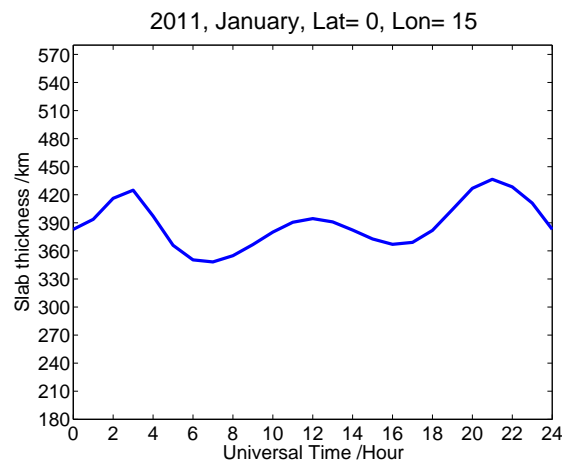

(c) January, Lat $=0 \mathrm{~N}$

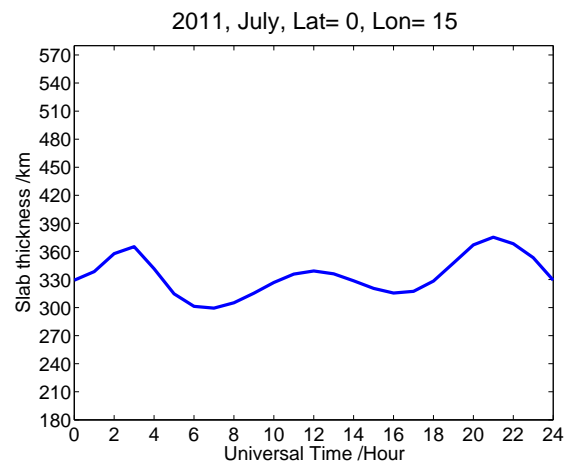

(f) July, Lat $=0 \mathrm{~N}$

Fig. 3. Variation of slab thickness, 2011.

show the mean diurnal and seasonal variations and effects of solar activity on the modeled $\tau$ values for low, middle and high latitudes. To calculate the modeled $\tau$ values we choose the months July and January of 2002 (a year of high solar activity) and July and January 2011 (low to medium solar activity). The solar radio flux index F10.7 ranges between 70 and 90 units (1 flux unit $=10^{-22} \mathrm{~W} \mathrm{~m}^{-2} \mathrm{~Hz}$ ) in January 2011 and between 85 and 125 units in July 2011. For 2002 the F10.7 values are between 180 and 255 units in January and between 130 and 250 units in July.

To model $\tau$ we calculate the values of TEC and $N m F 2$ by means of the models NTCM-GL and NPDM, respectively. The calculations are made for the latitudes 0,30 and 70 degrees north at 15 degrees east longitude. The latitudes $0^{\circ} \mathrm{N}$, $30^{\circ} \mathrm{N}$ and $70^{\circ} \mathrm{N}$ are chosen to cover low-, mid- and highlatitude regions. The longitude of 15 degrees east is chosen to make the considered slab thickness results comparable to the results of the $N m \mathrm{~F} 2$ validation performed in Sect. 5. Note that the most ionosonde stations considered in Sect. 5 are located around 15 degrees east of longitude. Since slab thickness modeling is just an interim result within this work, the consideration of the slab thickness results for any other longitudes is not included in this paper. In the next step we employ modeled $\mathrm{TEC}_{\text {mod }}$ and $\mathrm{NmF} 2_{\text {mod }}$ to calculate slab thick- ness according to the relation given by the Eq. (5). The slab thickness values are calculated every $60 \mathrm{~min}$ and afterwards averaged over the month.

Figure 3 shows the mean diurnal variations of $\tau$ for the summer month July and the winter month January during 2011 for low-, mid- and high-latitude locations. During the winter month the slab thickness values range between about 250 and $430 \mathrm{~km}$ for high-latitude, 240 and $350 \mathrm{~km}$ for midlatitude and 340 and $450 \mathrm{~km}$ for low-latitude location. In July the values are between 250 and $370 \mathrm{~km}$. For the mid- and low-latitudes, $\tau$ values seems to increase toward the equator. We observe two apparent peaks during the pre-midnight and pre-sunrise periods for the winter period for all three latitudes. Occurrence of similar pre-sunrise and post-sunset peaks in $\tau$ is reported by many investigators for different latitude regions (cf. Davies and Liu, 1991; Jayachandran et al., 2004; Chuo, 2007; Miro et al., 1999). The pre-sunrise peak of our modeled slab thickness is more pronounced during the winter period, in agreement with results of the mentioned papers. The nighttime values of modeled $\tau$ are higher compared to the daytime values during the winter month for all three latitudes. During July this relation seems to be true just for the low latitude. During solar minimum phases many observation-based investigations (cf. Jakowski et al., 1981; 


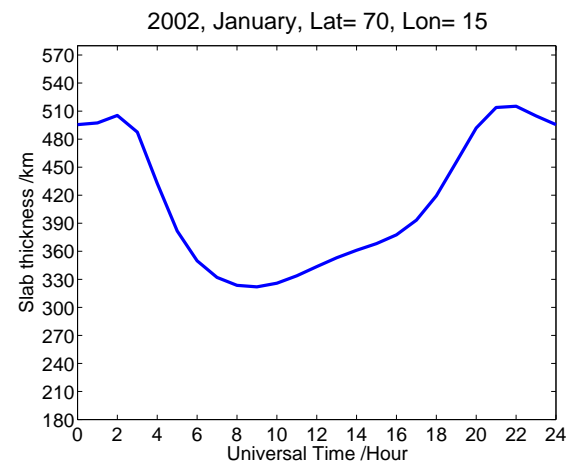

(a) January, Lat $=70 \mathrm{~N}$

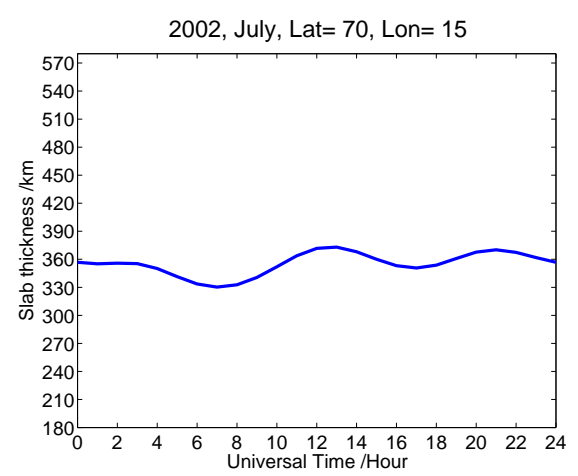

(d) July, Lat $=70 \mathrm{~N}$

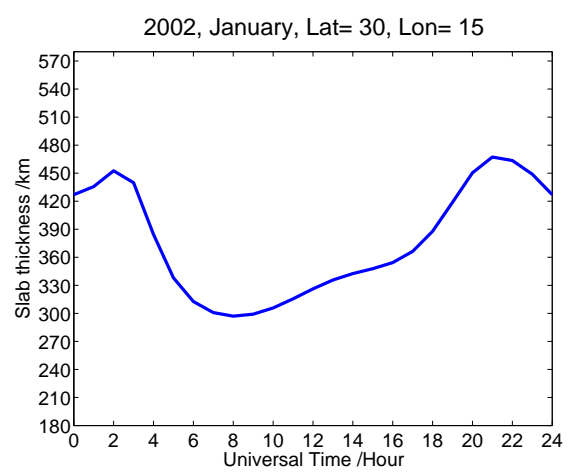

(b) January, Lat $=30 \mathrm{~N}$

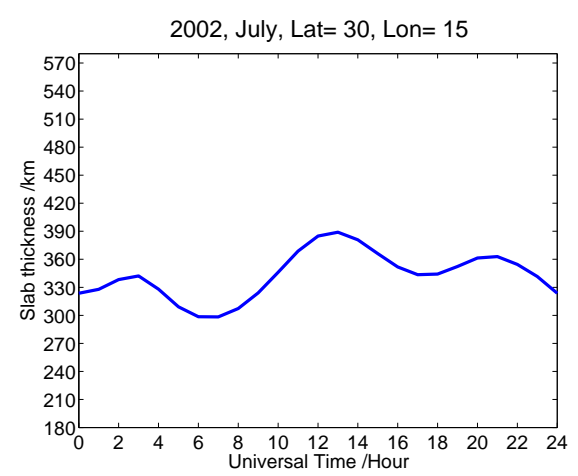

(e) July, Lat $=30 \mathrm{~N}$

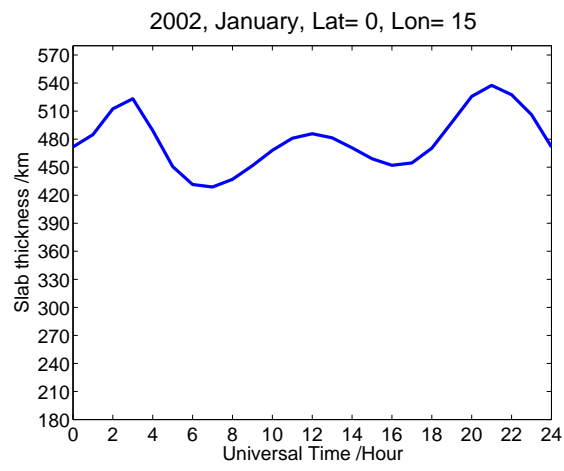

(c) January, Lat $=0 \mathrm{~N}$

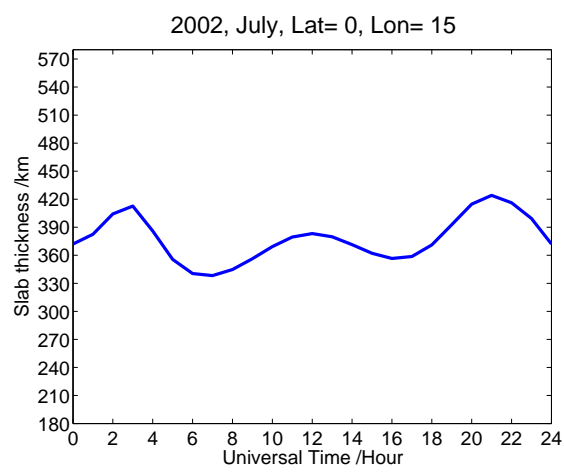

(f) July, Lat $=0 \mathrm{~N}$

Fig. 4. Variation of slab thickness, 2002.

Jayachandran et al., 2004; Chuo, 2007; Stankov and Warnant, 2009) generally characterize the mean diurnal variations of the slab thickness by nighttime values that are substantially higher than the daytime values during different seasons for different latitude locations except during the summer season for high and mid-latitudes.

Figure 4 represents the mean diurnal variation of the slab thickness for January and July during the solar maximum year 2002 again for the low-, mid- and high-latitude locations. We observe that the solar phase change has influenced the increase of $\tau$ values on all three latitudes for both summer and winter months. But for July the increase is much smaller than for the winter month. The slab thickness values range between 320 and $530 \mathrm{~km}$ for the high-latitude, 300 and $470 \mathrm{~km}$ for the mid-latitude and 430 and $540 \mathrm{~km}$ for the lowlatitude location during January. During July $\tau$ values are between 330 and $380 \mathrm{~km}, 300$ and $400 \mathrm{~km}$ and 340 and $420 \mathrm{~km}$ for high-, mid- and low-latitude locations, respectively. The increase agrees qualitatively with published results based on long-time observations of TEC and $f o \mathrm{~F} 2$ (cf. Jayachandran et al., 2004).

In conclusion we can say that our modeling results are comparable with other model- and observation-based investigations mentioned above.

\section{Validation of the reconstructed $N m \mathrm{~F} 2$ maps}

To test the proposed $N m \mathrm{~F} 2$ reconstruction algorithm we make a comparison between the reconstructed $N m \mathrm{~F} 2$ rec values and ionosonde data, $N m F 2_{\text {IS }}$, first and modeled $N m \mathrm{~F} 2_{\text {mod }}$ values and ionosonde data second. For validation the ionosonde stations' data of a one-month period, specifically July 2011 , is chosen. The data are selected at different latitudes in the Northern Hemisphere around two longitudes: $15^{\circ} \mathrm{E}$ and $130^{\circ} \mathrm{E}$.

Figure 5 presents the variation of the solar radio flux index F10.7 in flux units for July 2011. As mentioned before, the F10.7 index is a measure of the solar activity. The F10.7 data are obtained from the Space Physics Interactive Data Resource (SPIDR) of NOAA's National Geophysical Data Center (http://spidr.ngdc.noaa.gov/spidr/). As can be observed in Fig. 5 the validation period contains days with middle and low solar activity. The global planetary $3 \mathrm{~h}$ index Kp varies between 0 and 5 units; thus also the geomagnetic activity is low to middle. Please note that the $\mathrm{Kp}$ index is given here just as a measure for the geomagnetic activity. It is not an input parameter for the NPDM model.

As a reference data set we used ionosonde data from the stations Troms $\varnothing$, Juliusruh, Rome, Gibilmanna, Magadan, 


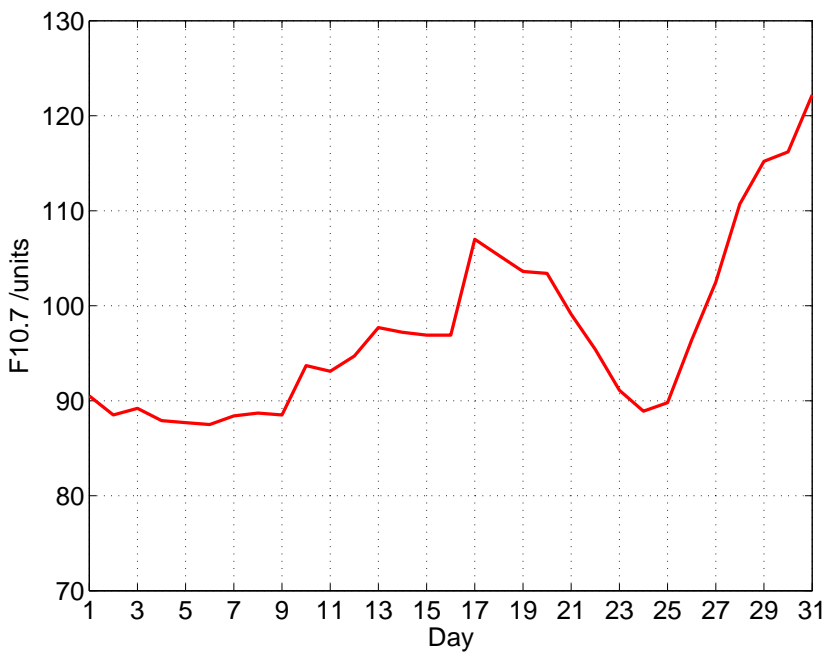

Fig. 5. The F10.7 (solar radio flux) index for July 2011.

I-Cheon and Okinawa. The ionosonde data are obtained from the National Geophysical Data Center. Table 1 shows the list of all used ionosonde stations with geographical locations.

First of all, the ionosonde data are filtered by a plausibility check. The plausibility check algorithm sorts out the values above $10^{13} \mathrm{~m}^{-3}$ or under $10^{10} \mathrm{~m}^{-3}$ if the corresponding measured TEC values were neither unexpectedly high nor low. In parallel to this the $N m \mathrm{~F} 2$ values are calculated applying both the NPDM Model and the reconstruction algorithm for the ionosonde station locations and time steps of availability of the ionosonde measurements.

The histograms of the $N m \mathrm{~F} 2$ model residuals, $N m \mathrm{~F} 2$ IS $N m \mathrm{~F} 2_{\text {mod }}$, and reconstruction residuals, $N m \mathrm{~F} 2_{\mathrm{IS}}-N m \mathrm{~F} 2_{\text {rec }}$, are shown in Fig. 6. The left-side picture presents the histogram of the reconstruction residuals as well as the corresponding mean, root mean square (rms) and standard deviation, and the right one the model residuals histogram. We can see that the residuals are normally distributed with a mean value of $-2.4 \times 10^{10}$ for the reconstruction and $4.2 \times 10^{10}$ for the model residuals. The standard deviations are $13 \times 10^{10}$ and the rms deviation is $13.2 \times 10^{10}$ for the reconstruction and $13.7 \times 10^{10}$ for the model.

To get a first impression on the reconstruction results under disturbed conditions, we compare the reconstructed and modeled $N m \mathrm{~F} 2$ values with ionosonde data for a day with a F10.7 jump and a day with stabile and low solar activity during the validation period July 2011. As can be seen in Fig. 5 we have a local F10.7 peak on 17 July 2011; thus this day is selected. As a quiet day we choose 8 July 2011, because the F10.7 values during some days around 8 July stay nearly constant. As a reference data set we use again the ionosonde data from the stations Troms $\varnothing$, Juliusruh, Rome, Gibilmanna, Magadan, I-Cheon and Okinawa. The residuals are calculated in the same way as described above. Figure 7 shows the histograms of the model and reconstruction resid-
Table 1. Ionosonde stations used for the validation.

\begin{tabular}{lllll}
\hline Code & Name & Country & Latitude & Longitude \\
\hline TR170 & Troms $\varnothing$ & Norway & $69.6^{\circ} \mathrm{N}$ & $19.2^{\circ} \mathrm{E}$ \\
JR055 & Juliusruh & Germany & $54.6^{\circ} \mathrm{N}$ & $13.4^{\circ} \mathrm{E}$ \\
RO041 & Rome & Italy & $41.8^{\circ} \mathrm{N}$ & $12.5^{\circ} \mathrm{E}$ \\
GM037 & Gibilmanna & Italy & $37.6^{\circ} \mathrm{N}$ & $14^{\circ} \mathrm{E}$ \\
MG560 & Magadan & Russia & $60^{\circ} \mathrm{N}$ & $151^{\circ} \mathrm{E}$ \\
IC437 & I-Cheon & South Korea & $37.1^{\circ} \mathrm{N}$ & $127.5^{\circ} \mathrm{E}$ \\
OK426 & Okinawa & Japan & $26.3^{\circ} \mathrm{N}$ & $127.8^{\circ} \mathrm{E}$ \\
\hline
\end{tabular}

uals for the two picked-out days: 17 July 2011 (panels a and b) and 8 July 2011 (panels c and d).

We can observe that the values of the residual distributions for 8 July are nearly equal to the corresponding values calculated for the whole month (cf. Fig. 6) for both reconstructed and model residuals. However, for 17 July the picture of the residual distribution values is significantly changed. The mean of the model residuals increases from $4.2 \times 10^{10}$ averaged over the whole of July to $7.3 \times 10^{10}$ for 17 July, while the mean value of the reconstruction residuals decreases to $0.6 \times 10^{10}$. Thus, for this day with a F10.7 peak we observe an improvement of the mean residuals by a factor of 12.17 , comparing the reconstruction and the model. The standard deviation is slightly increased for both reconstruction and model residuals, which is not unexpected for disturbed conditions. Due to the fact that within the reconstruction not only the F10.7 value but also actual TEC measurements are used, we expect that for periods of high solar activity and also during solar storms the reconstruction provides much more accurate results than the model. The next step will be to compare the reconstructed and modeled $N m \mathrm{~F} 2$ values with measurements for a time period with high solar activity.

In conclusion we can say that both the model and the reconstruction approach provide similar good results, but the reconstruction has a factor of 1.75 better mean value for the observed period with low to middle solar activity. It should be noted that the results and the quality of this reconstruction approach strongly depend on the model slab thickness values. And these values essentially depend on the quality of the TEC and $N m \mathrm{~F} 2$ models and on the condition that these two models fit together.

\section{Conclusions}

This paper presents the reconstruction approach for the F2 layer peak electron density. The main input for the reconstruction procedure is the TEC maps calculated from groundbased GNSS measurements. The algorithm can be run on a global or a local grid. The spatial resolution can be easily modified.

Currently the algorithm is used for routine generation of global $N m \mathrm{~F} 2$ maps with spatial resolution of $2.5^{\circ}$ latitude, 


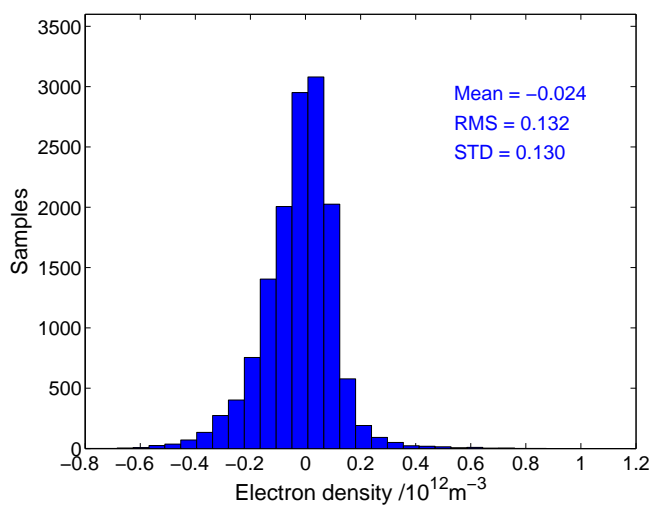

(a) $N m F 2_{I S}-N m F 2_{r e c}$

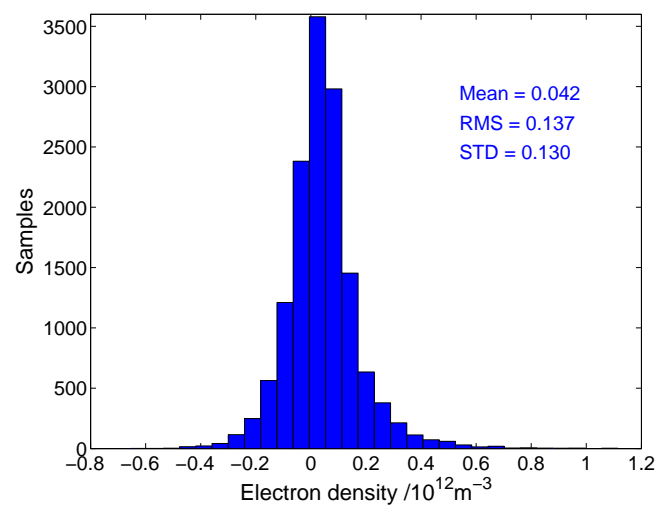

(b) $N m F 2_{I S}-N m F 2_{m o d}$

Fig. 6. Histograms of the residuals, July 2011. Reconstruction residuals are on the left side and model residuals on the right.

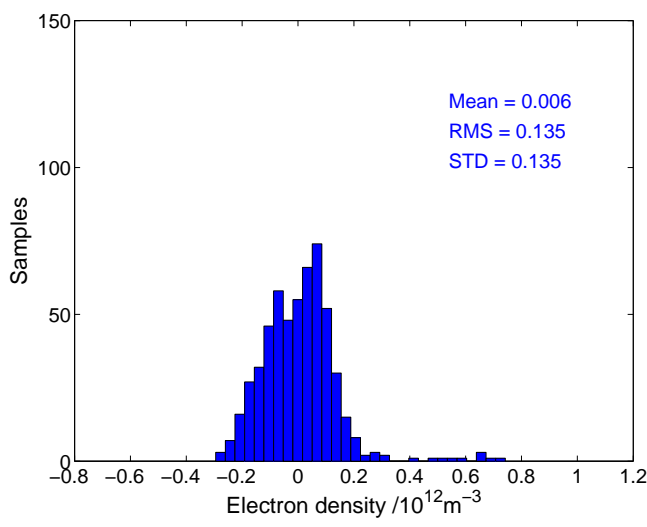

(a) $N m F 2_{I S}-N m F 2_{\text {rec }}, 17 / 07 / 2011$

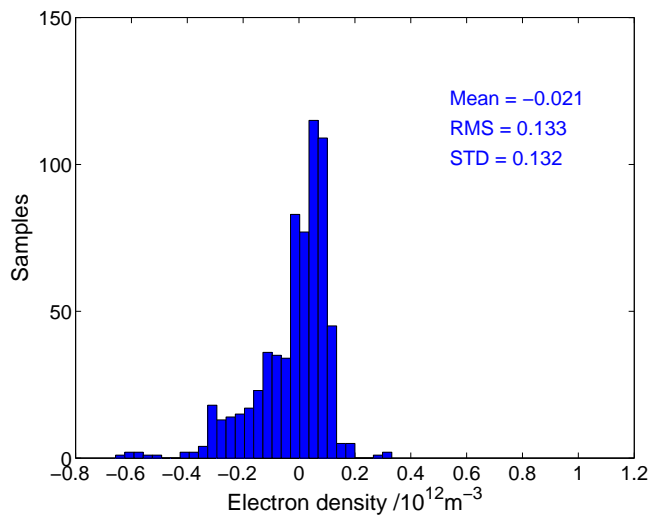

(c) $N m F 2_{I S}-N m F 2_{r e c}, 08 / 07 / 2011$

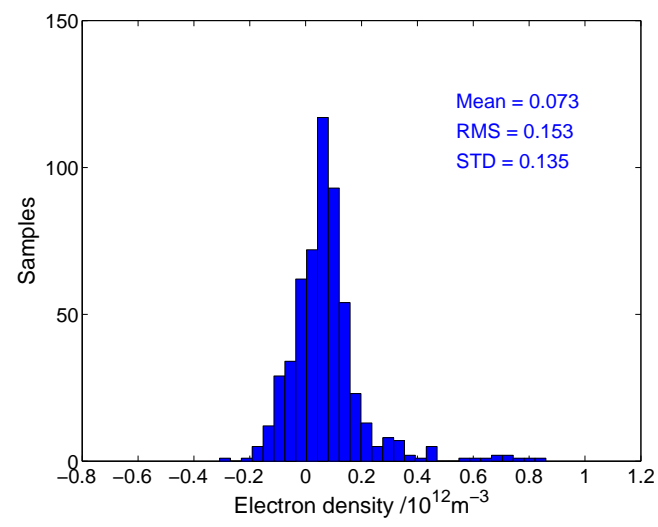

(b) $N m F 2_{I S}-N m F 2_{\text {mod }}, 17 / 07 / 2011$

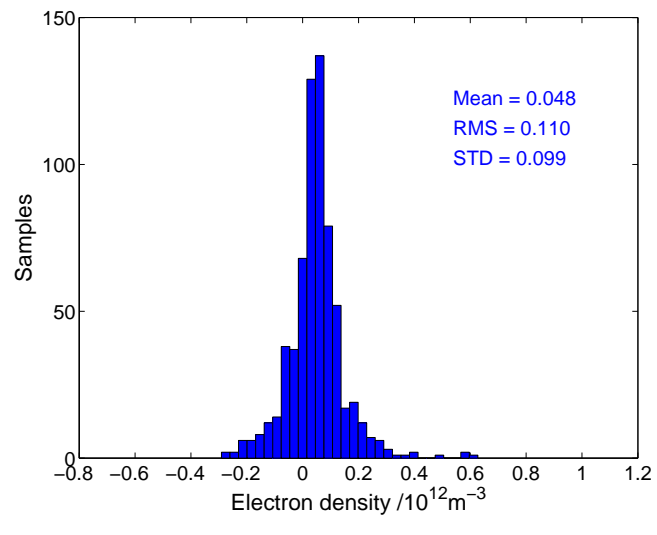

(d) $N m F 2_{I S}-N m F 2_{\text {mod }}, 08 / 07 / 2011$

Fig. 7. Histograms of the reconstruction residuals (left side) and model residuals (right side).

$5^{\circ}$ longitude and time resolution of $5 \mathrm{~min}$. The reconstructed electron density maps are offered to users via the operational data service SWACI (http://swaciweb.dlr.de) at DLR Neustrelitz.

The presented reconstruction method provides the users the possibility to get an improved picture of the actual iono- sphere. They are fast and easy in application and suitable for the operational service. Comparing the $N m \mathrm{~F} 2$ reconstruction and NPDM model with ionosonde data an improvement of the mean residuals by a factor 1.75 have been observed. For the standard and rms deviations we get similar results. 
Our next steps will be to validate the presented reconstruction method under different solar and geomagnetic activity conditions and to improve the method by assimilation of the ionosonde measurements.

Acknowledgements. The authors thank the IGS for making available high-quality GPS observation data. The authors are also grateful to NGDC for disseminating ionosonde data via SPIDR. Many thanks also to the reviewers of the manuscript for very helpful comments.

The service charges for this open access publication have been covered by a Research Centre of the Helmholtz Association.

Topical Editor K. Kauristie thanks two anonymous referees for their help in evaluating this paper.

\section{References}

Angling, M. J. and Cannon, P. S.: Assimilation of radio occultation measurements into background ionospheric models, Radio Sci., 39, RS1S08, doi:10.1029/2002RS002819, 2004.

Angling, M. J. and Khattatov, B.: Comparative study of two assimilative models of the ionosphere, Radio Sci., 41, RS5S20, doi:10.1029/2005RS003372, 2006.

Bust, G. S., Garner, T. W., and Gaussiran II, T. L.: Ionospheric Data Assimilation Three-Dimensional (IDA3D): A global, multisensor, electron density specification algorithm, J. Geophys. Res., 109, A11312, doi:10.1029/2003JA010234, 2004.

Bust, G. S. and Mitchell, C. N.: History, current state, and future directions of ionospheric imaging, Reviews of Geoph., 46, 23 pp., 2008.

Chuo, Y. J.: The variation of ionospheric slab thickness over equatorial ionization area crest region, J. Atmos. Terr. Phys., 69, 947954, 2007.

Davies, K.: Ionospheric Radio, Peter Peregrinus Ltd, London, 1990.

Davies, K. and Liu, X. M.: Ionospheric slab thickness in middle and low latitudes, Radio Sci., 26, 997-1005, 1991.

Hernández-Pajares, M., Juan, J. M., Sanz, J., Orus, R., Garcia-Rigo, A., Feltens, J., Komjathy, A., Schaer, S. C., and Krankowski, A.: The IGS VTEC maps: a reliable source of ionospheric information since 1998, J. Geod., 83, 263-275, doi:10.1007/s00190-0080266-1, 2009.

Hoque, M. M. and Jakowski, N.: Estimate of higher order ionospheric errors in GNSS positioning, Radio Sci., 43, RS5008, doi:10.1029/2007RS003817, 2008.

Hoque, M. M. and Jakowski, N.: A new global empirical $N m \mathrm{~F} 2$ model for operational use in radio systems, Radio Sci., 46, RS6015, doi:10.1029/2011RS004807, 2011.
Huang, Y.-N.: Some results of ionospheric slab thickness observations at Lunping, J. Geophys. Res., 88, 5517-5522, 1983.

Jakowski, N., Bettac, H. D., Lazo, B., and Lois, L.: Seasonal variations of the columnar electron content of the ionosphere observed in Havana from July 1974 to April 1975, J. Atmos. Terrestrial Phys., 43, 7-11, 1981.

Jakowski, N., Putz, E., and Spalla, P.: Ionospheric storm characteristics deduced from satellite radio beacon observations at three European stations, Ann. Geophys. 8, 343-352, 1990.

Jakowski, N., Mielich, J., Hoque, M. M., and Danielides, M.: Equivalent slab thickness at the mid-latitude ionosphere during solar cycle 23, 38th COSPAR Scientific Assembly, 18-25 July 2010, Bremen, Germany, 2010.

Jakowski, N., Hoque, M. M., and Mayer, C.: A new global TEC model for estimating transionospheric radio wave propagation errors, J. Geod., 85, 965-974, doi:10.1007/s00190-011-0455-1, $2011 \mathrm{a}$.

Jakowski, N., Mayer, C., Hoque, M. M., and Wilken, V.: Total Electron Content Models And Their Use In Ionosphere Monitoring, Radio Sci., 46, RS0D18, doi:10.1029/2010RS004620, 2011 b.

Jayachandran, B., Krishnankutty, T. N., and Gulyaeva, T. L.: Climatology of ionospheric slab thickness, Ann. Geophys., 22, 25-33, doi:10.5194/angeo-22-25-2004, 2004.

Kersley, L. and Hajeb-Hosseinieh, H.: The dependence of ionospheric slab thickness on geomagnetic activity, J. Atmos. Terr. Phys., 38, 1357-1360, 1976.

Leitinger, R., Ciraolo, L., Kersley, L., Kouris, S. S., and Spalla, P.: Relations between electron content and peak density-regular and extreme behaviour, Ann. Geophys. Suppl., 47, 179-194, 2004.

Miro, G., Jakowski, N., and de la Morena, B. A.: Equivalent Slab Thickness of the Ionosphere in Middle Latitudes Based on TEC/fOF2 Observations Over EL Arenosillo, in: Proc. 3rd COST251 Workshop, edited by: Hanbaba, R. and de la Morena, B. A., September, 1998, 87-92, 1999.

Nava, B., Coisson, P., and Radicella, S. M.: A new version of the NeQuick ionosphere electron density model, J. Atmos. Solar Terr. Phys., 70, 1856-1862, doi:10.1016/j.jastp.2008.01.015, 2008.

Scherliess, L., Schunk, R. W., Sojka, J. J., and Thompson, D. C.: Development of a physics-based reduced state Kalman filter for the ionosphere, Radio Sci., 39, RS1S04, doi:10.1029/2002RS002797, 2004.

Stankov, S. M. and Jakowski, N.: Topside ionospheric scale height analysis and modeling based on radio occultation measurements, J. Atmos. Solar-Terr. Phys., 68, 134-162, 2006.

Stankov, S. M. and Warnant, R.: Ionospheric slab thickness - Analysis, modelling and monitoring, Adv. Space Res., 44, 1295-1303.

Unglaub, C., Jacobi, Ch., Schmidtke, G., Nikutowski, B., and Brunner, R.: EUV-TEC proxy to describe ionospheric variability using satellite-borne solar EUV measurements: First results, Adv. Space Res., 47, 1578-1584, 2011. 